\title{
A Large-capacity DC-DC Converter with Input-Series-Input-Parallel Output-Series-Output-Parallel Connection
}

\author{
Zhenghong Tu, ${ }^{1, a}$, Xin Wang ${ }^{1, b^{*}}$, Yihui Zheng ${ }^{1}$, Lixue Li ${ }^{1}$, Guo Chen ${ }^{2}$ and Feng \\ $\mathrm{Zhu}^{2}$ \\ ${ }^{1}$ Center of Electrical \& Electronic Technology, Shanghai Jiao Tong University, Shanghai, China \\ ${ }^{2}$ Guang'an Power Supply Company of State Grid Sichuan Electric Power Company, China \\ atutujiayou68@sjtu.edu.cn, ${ }^{b}$ wangxin26@sjtu.edu.cn \\ "corresponding author: wangxin26@sjtu.edu.cn
}

Keywords: large-capacity, Input-series-input-parallel output-series-output-parallel connection, DC-DC converter, Output-voltage control

Abstract. In order to improve the capacity of DC-DC converter, a large-capacity DC-DC converter with input-series-input-parallel output-series-output-parallel (ISIPOSOP) connection is proposed in this paper. The converter consisting of multiple basic DC-DC modules has the ability to withstand the high voltage and large current at both sides. Firstly, the paper presents the structure of ISIPOSOP DC-DC converter. Its characteristic of withstanding high voltage and large current at both sides is concluded in theory. Secondly, for fulfilling the fast stability of the output voltage of the ISIPOSOP system, an output-voltage control strategy based on an approximate small signal model is proposed. The strategy distributes the load to establish an approximate small signal model. Then the controller designed by using this model helps to realize the fast stability of output voltage. Finally, simulation of an ISIPOSOP system is given. The results verify the fast output-voltage tracking effect of the strategy.

\section{Introduction}

DC-grid technology is an effective method to realize the large power transmission, the reliable operation of the interconnected AC grids, and the integration of renewable energy. DC-DC converter is one of the main components in DC grids. But so far, the research of the DC-DC converter is mainly focused on the medium or low voltage and low power.

For these reasons, two kinds of input-series output-series (ISOS) large-capacity DC-DC converter have been proposed in [1,2], both of them are suitable for high input and output voltage applications. However, ISOS DC-DC converter cannot be applied in large output-current situation. Then in [3], an input-series output-parallel (ISOP) large-capacity DC-DC converter is proposed. In addition, the input-parallel output-parallel (IPOP) converter is discussed in [4,5], and the input-parallel output-series (IPOS) converter is described in [6]. Even though DC-DC converters in [1]-[6] overcome the low capacity shortcomings of traditional DC-DC converters, their scope of application is still not very considerable.

Accordingly, the input-series-input-parallel output-series-output-parallel (ISIPOSOP) DC-DC converter is proposed in the paper in order to improve the capacity of DC-DC converters. Firstly, the structures of ISIPOSOP converter and ISOS, ISOP, IPOP, IPOS converter are compared. The concluded feature of ISIPOSOP converter is that it can achieve DC-DC conversion with high voltage and large current at both sides. Secondly, a control strategy is presented to fulfill the fast stability of the output voltage. The strategy adopts an approximate small signal model instead of the accurate one, thus the output-voltage controller of the system can be obtained more easily. Finally, an ISIPOSOP system composed of 4 modules is simulated. The simulation results prove that the method above has a good ability to track the output voltage quickly. 


\section{Structure Analysis of the ISIPOSOP DC-DC Converter}

The paper proposes the ISIPOSOP DC-DC converter in Fig. 1. Assuming the basic modules of the following converters have the same circuit parameters, then the input voltage rating of each module is $V_{i}^{\prime}$, its input current rating is $I_{i}^{\prime}$, its output voltage rating is $V_{o}^{\prime}$, and its output current rating is $I_{o}^{\prime}$.

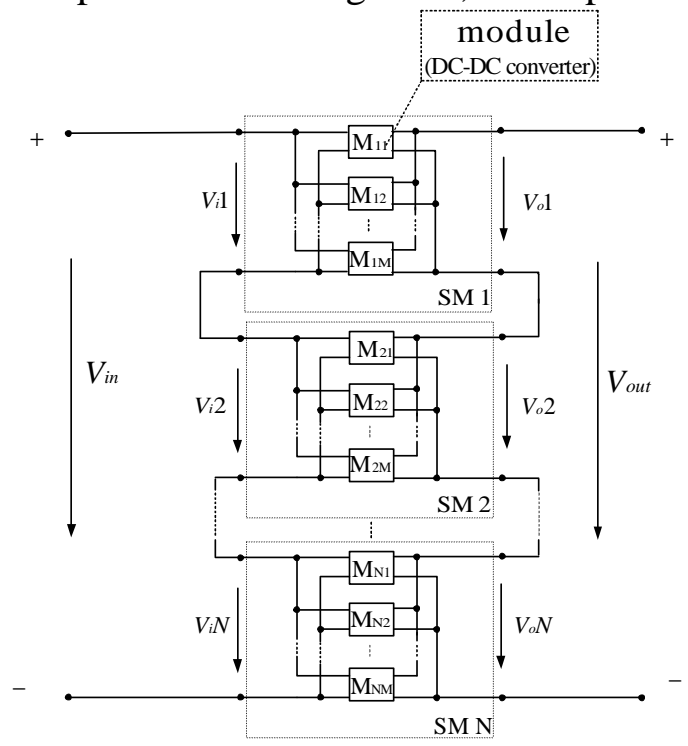

Fig. 1. ISIPOSOP DC-DC converter consisting of MN modules

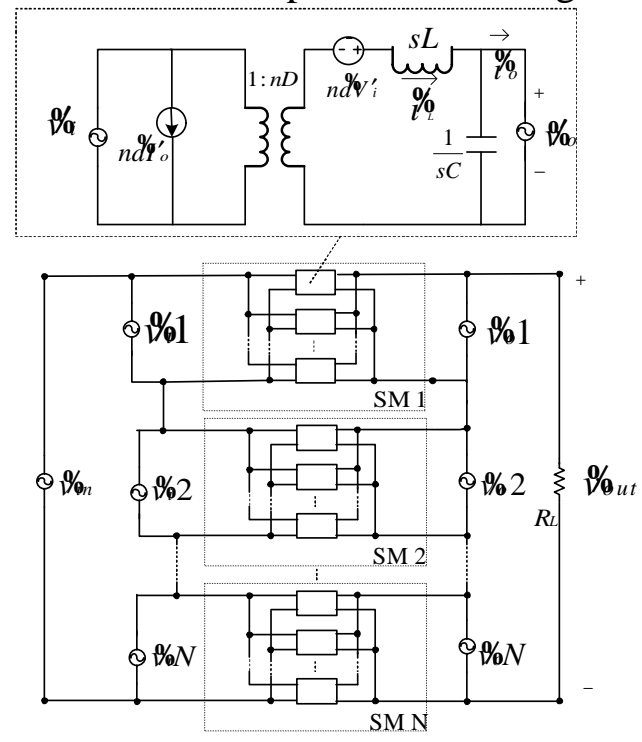

Fig. 2. Small signal model of ISIPOSOP converter (MN modules)

The ISIPOSOP DC-DC converter composed of MN modules, IPOP converter composed of M modules, the IPOS converter composed of M modules, the ISOP converter composed of $\mathrm{N}$ modules, the ISOS converter consisting of $\mathrm{N}$ converter are compared in the matter of the voltage and current rating at both sides. In Table 1, the voltage and current rating of the ISIPOSOP DC-DC converter are the highest. The conclusion is that ISIPOSOP converter consisting of more modules can achieve DC-DC transform with higher voltage and larger current at both sides.

Table 1. Comparison of the five kinds of connection

\begin{tabular}{|c|c|c|c|c|}
\hline Type of connection & $\begin{array}{c}\text { Input voltage } \\
\text { rating }\end{array}$ & $\begin{array}{c}\text { Input current } \\
\text { rating }\end{array}$ & $\begin{array}{c}\text { Output voltage } \\
\text { rating }\end{array}$ & $\begin{array}{c}\text { Output current } \\
\text { rating }\end{array}$ \\
\hline IPOP(M modules) & $V_{i}^{\prime}$ & $M I^{\prime}$ & $V_{o}^{\prime}$ & $M I_{o}^{\prime}$ \\
\hline IPOS(M modules) & $V_{i}^{\prime}$ & $M I_{i}^{\prime}$ & $M V_{o}^{\prime}$ & $I_{o}^{\prime}$ \\
\hline ISOP(N modules) & $N V_{i}^{\prime}$ & $I_{i}^{\prime}$ & $V_{o}^{\prime}$ & $N I_{o}^{\prime}$ \\
\hline ISOS(N modules) & $N V_{i}^{\prime}$ & $I_{i}^{\prime}$ & $N V_{o}^{\prime}$ & $I_{o}^{\prime}$ \\
\hline ISIPOSOP(MN modules) & $N V_{i}^{\prime}$ & $M I_{i}^{\prime}$ & $N V_{o}^{\prime}$ & $M I_{o}^{\prime}$ \\
\hline
\end{tabular}

\section{Output-Voltage Control Strategy Analysis of the ISIPOSOP Converter}

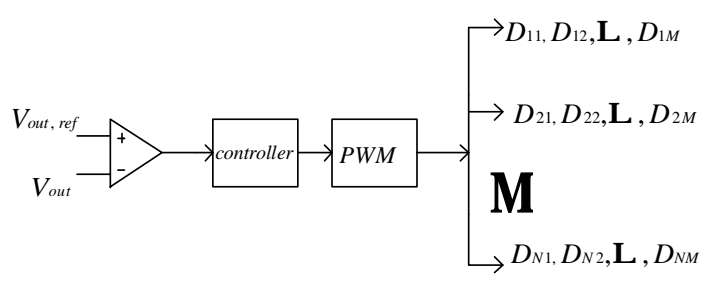

Fig. 3. Output-voltage control strategy of the ISIPOSOP converter.

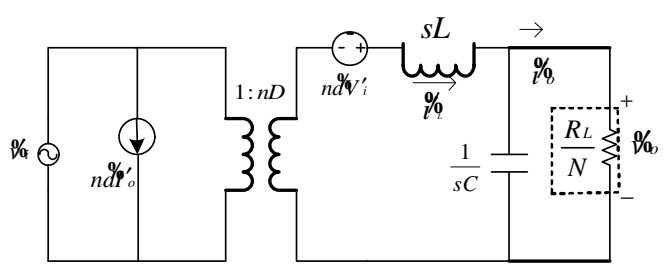

Fig. 4. Approximate small signal model of each module.

The small signal model can be used to achieve the linear control of the DC-DC converter. The model of ISIPOSOP converter (MN full-bridge isolated DC-DC modules) is shown in Fig. 2. $d^{2}\left(d_{i j}, \mathrm{i}=1,2,3, \ldots\right.$ ,N. $\mathrm{j}=1,2,3, \ldots, \mathrm{M})$ is the duty cycle perturbation of each module. $\$ / \%(\% / \mathrm{g}, \mathrm{i}=1,2,3, \ldots, \mathrm{N} . \mathrm{j}=1,2,3, \ldots, \mathrm{M})$ is the output voltage perturbation of each module. The symbol $\%$ at stands for the output voltage 
perturbation of the system. Since it is difficult to control the duty cycle of each module separately, a control strategy proposed is to use the same duty cycle control for each module as shown in Fig. 3. This strategy helps to stabilize the output voltage. In addition, the small signal model of ISIPOSOP system is also very complicated, so this paper presents an approximate small signal model with the average distribution of the load. In Fig. 4, if the load of the ISIPOSOP system is $R_{L}$, then the load of the model is $R_{L} / N$. Controller design is based on the approximate model.

$$
\begin{aligned}
& \frac{\vartheta \%}{q_{i j}}=\frac{n V_{i n}}{1+s \frac{N L}{R_{L}}+s^{2} L C} \quad(\mathrm{i}=1,2,3, \mathrm{~L} \quad, \mathrm{~N} ; \mathrm{j}=1,2,3, \mathrm{~L}, \mathrm{M}) . \\
& \frac{16 Q_{t}}{\mathscr{d}_{i j}}=\frac{n N V_{i n}}{1+s \frac{N L}{R_{L}}+s^{2} L C} \quad(\mathrm{i}=1,2,3, \mathrm{~L} \quad, \mathrm{~N} ; \mathrm{j}=1,2,3, \mathrm{~L}, \mathrm{M}) .
\end{aligned}
$$

In the small signal model of each module, the relationship between $d_{i j} / \mathrm{c}$ and $\mathrm{i} \%$ is expressed in $\mathrm{s}$

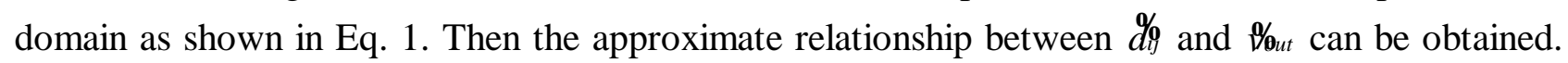
Output voltage of the ISIPOSOP system is controlled by a PID controller designed by using Eq. 2.

\section{Simulation of ISIPOSOP DC-DC Converter Consisting of Four Modules}

Table 2. Specifications of the ISIPOSOP converter

\begin{tabular}{|c|c|}
\hline Item & Value \\
\hline Input voltage & $4000[\mathrm{~V}] \sim 7000[\mathrm{~V}]$ \\
\hline Output voltage & $14400[\mathrm{~V}]$ \\
\hline $\begin{array}{c}\text { Maximum output } \\
\text { voltage ripple }\end{array}$ & $0.5 \% V_{o}$ \\
\hline $\begin{array}{c}\text { Switching } \\
\text { frequency }\end{array}$ & $100[\mathrm{KHz}]$ \\
\hline
\end{tabular}

Table 3. Designed component values of the ISIPOSOP DC-DC converter

\begin{tabular}{|c|c|c|}
\hline Item & Symbol & Value \\
\hline Number of modules & $\mathrm{MN}$ & 4 \\
\hline Filter inductance & $\mathrm{L}$ & $100[\mu \mathrm{H}]$ \\
\hline Filter capacitance & $\mathrm{C}$ & $100[\mu \mathrm{F}]$ \\
\hline Turns ratio & $1: \mathrm{n}$ & $1: 4$ \\
\hline Load resistance & $\mathrm{R}_{\mathrm{L}}$ & $20[\Omega]$ \\
\hline PID controller & $\mathrm{K}_{\mathrm{c}}(\mathrm{s})$ & $0.011175 / s$ \\
\hline
\end{tabular}

This section introduces the simulation of the ISIPOSOP Converter (4 full-bridge isolated DC-DC modules). The specifications of the converter are given in Table 2. Component values are designed as shown in Table 3.As shown in Fig. 5, the simulation results are achieved by using software PLECS. When the input voltage is set at $4000 \mathrm{~V}, 5000 \mathrm{~V}, 6000 \mathrm{~V}$ and $7000 \mathrm{~V}, \mathrm{~V}_{\text {out }}$ can be stabilized at $14400 \mathrm{~V}$ in less than 0.08s. The output voltage ripple is acceptable. Hence, it is concluded that the ISIPOSOP system with this control strategy can realize stable output voltage in a high speed.

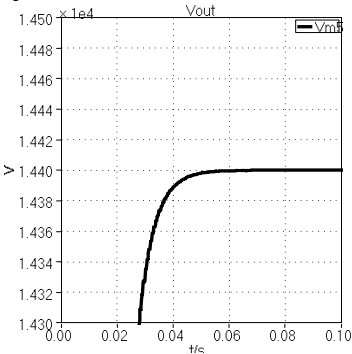

(a)

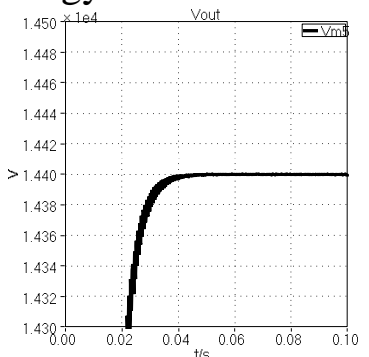

(b)

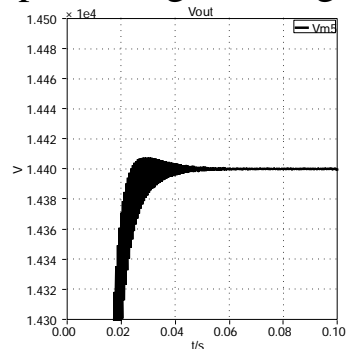

(c)

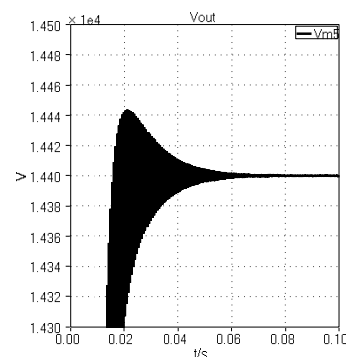

(d)

Fig. 5. Output voltage of the ISIPOSOP system.(a)when the input voltage is $4000 \mathrm{~V}$. (b) when the input voltage is $5000 \mathrm{~V}$. (c) when the input voltage is $6000 \mathrm{~V}$. (d) when the input voltage is $7000 \mathrm{~V}$.

When the input voltage is $5000 \mathrm{~V}$, output voltage of each module and the ISIPOSOP system is in Fig. 6 . In the case of match in all components, output voltages of the 4 modules are much the same. When filter inductance and capacitance in the 4 modules have some differences, $V_{\circ} 1, V_{o} 2$ are some different 
from $\mathrm{V}_{\mathrm{o}} 3$ and $\mathrm{V}_{\mathrm{o}} 4$, but $\mathrm{V}_{\text {out }}$ is also stable in less than $0.08 \mathrm{~s}$. Then the conclusion is that the output-voltage control strategy is still effective when modules have some acceptable mismatch.

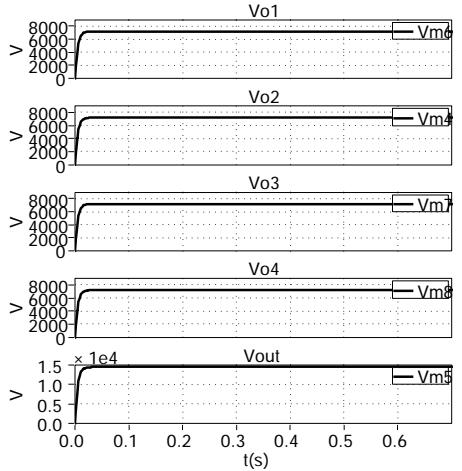

(a)

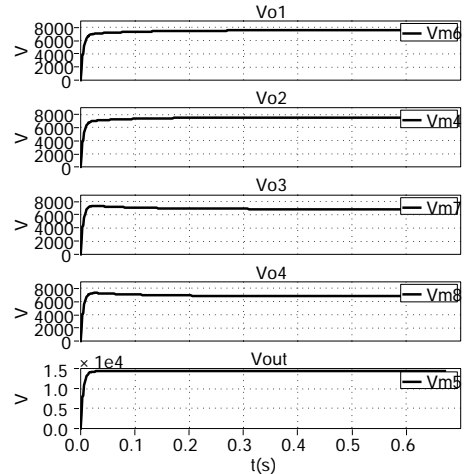

(b)

Fig. 6. Output voltage of each module and the ISIPOSOP system when input voltage is 5000V.(a) case of match in all components.(b)case of mismatch in filter inductance and capacitance (4 component values are changed from the designed values, $\mathrm{L}_{11}=110 \mu \mathrm{H}, \mathrm{C}_{12}=110 \mu \mathrm{F}, \mathrm{L}_{21}=90 \mu \mathrm{H}, \mathrm{C}_{22}=90 \mu \mathrm{F}$ ).

\section{Conclusions}

In this paper, a large-capacity ISIPOSOP DC-DC converter composed of basic DC-DC modules is proposed. First, the converter is compared with 4 other kinds of converters in the matter of the structure. It can be concluded that the ISIPOSOP connection can realize DC-DC transform with higher voltage and larger current at both sides. Then, according to the approximate small signal model based on the accurate model, an output-voltage control strategy is presented to achieve the stable output voltage. Finally, an ISIPOSOP converter consisting of four modules is taken as an example to be simulated. The simulation results have verified the fast output voltage tracking effect of the strategy.

\section{Acknowledgements}

This work is supported by the Key Project of NSFC (No. 61533012), the Shanghai Natural Science Foundation (14ZR1421800), the State Key Laboratory of Synthetical Automation for Process Industries.

\section{References}

[1] A.J.B. Bottion, I. Barbi, Series-series association of two dual active bridge (DAB) converters, IEEE International Conference on Industrial Technology (ICIT), (2015) 1161-1166.

[2] W. Chen, G. Wang, Decentralized voltage-sharing control strategy for fully modular input-series-output-series system with improved voltage regulation, IEEE Transactions on Industrial Electronics. 62 (2015) 2777-2787.

[3] X. Ruan, W. Chen, L. Cheng, Control strategy for input-series-output-parallel converters, IEEE Transactions on Industrial Electronics. 56 (2009) 1174-1185.

[4] J. Shi, T. Liu, J. Cheng, and X. He, Automatic current sharing of an input-parallel output-parallel (IPOP)-connected DC-DC converter system with chain-connected rectifiers, IEEE Transactions on Power Electronics. 30 (2015) 2997-3015.

[5] J. Shi, L. Zhou, and X. He, Common-duty-ratio control of input-parallel output-parallel (IPOP) connected DC-DC converter modules with automatic sharing of currents, IEEE Transactions on Power Electronics. 27 (2015) 3277-3291. 
[6] W. Chen, X. Ruan, H. Yan, and C. K. Tse, DC/DC conversion systems consisting of multiple converter modules: Stability, control, and experimental verifications, IEEE Transactions on Power Electronics. 24 (2009) 1463-1474. 